\title{
Concepções de acadêmicos de enfermagem acerca da depressão e do cuidado ao paciente deprimido
}

\author{
Concepts by nursing scholars about depression and care for \\ depressed patients
}

\author{
Marina Gabriela Medeiros de Moura* \\ Izayana Pereira Feitosa* \\ Glenda Agra* \\ Gigliola Marcos Bernardo de Lima* \\ Itacira Pedrosa de Lima* \\ Polianna Alves Sucupira*
}

\begin{abstract}
Resumo
O transtorno depressivo é o transtorno mental mais comum e é considerado um grave problema de saúde pública. Acredita-se que o conhecimento acerca da depressão é de fundamental importância para o profissional de enfermagem, haja vista seu papel no contato direto com o paciente, agindo como participante ativo na identificação e tratamento dos diversos transtornos mentais. Este estudo teve como objetivo conhecer as concepções sobre depressão dos acadêmicos do curso de Enfermagem da Universidade Federal de Campina Grande, Campus Cuité. Trata-se de um estudo descritivo sob a perspectiva da abordagem qualitativa, realizado através da participação de discentes de enfermagem que responderam a um questionário semiestruturado versado sobre a temática da depressão. Os resultados foram analisados por meio da técnica da análise de conteúdo proposta por Bardin. Os resultados demonstraram que a maioria dos alunos julga seu conhecimento como bom ou regular e justificaram-se, sobretudo, na necessidade de aperfeiçoamento e falta de campo prático. Observou-se também, que os participantes, apesar das respostas mostradas anteriormente, explanaram uma assistência de enfermagem pertinente, holística e humanizada. Quanto à didática, os discentes apresentaram o método tradicional como preponderante no ensino do distúrbio e propuseram que melhorias no ensino poderiam ser alcançadas com o uso de metodologias ativas e articulação da teoria com a prática.
\end{abstract}

Palavras-chave: Depressão. Estudantes. Enfermagem.

\begin{abstract}
Depressive disorder is the most common mental disorder and it is considered a serious public health problem. It is believed that knowledge about depression has a fundamental importance for professional nurses, given their role implies a direct contact with patienst, acting as an active participant in the identification and treatment of various mental disorders. This study aimed to identify the concepts about depression of academics of an undergraduate nursing course at Federal University of Campina Grande, Campus Cuité, Paraíba. This is a descriptive study under the perspective of a qualitative approach, carried out through the participation of nursing students who responded to a semi-structured questionnaire versed on the subject of depression. The results were analyzed by means of the technique of content analysis proposed by Bardin. The results showed that most students judge their knowledge as good or regular and they gave justified it in particular by means of the need for improvement and lack of practical field work. It is also noted that participants, despite the responses shown previously, have also shown in their answers an important, holistic and humane conception of nursing care. As for didactics, the students presented the traditional method as preponderant in teaching about the disorder and proposed that improvements in education could be achieved with the use of active methodologies and articulation of theory with practice.
\end{abstract}

Keywords: Depression. Students. Nursing.

DOI: 10.15343/0104-7809.20153902219230

* Universidade Federal De Campina Grande (UFCG), campus Cuité. Paraíba, Brasil E-mail: gab.iimoura@hotmail.com

As autoras declaram não haver conflito de interesses. 


\section{INTRODUÇÃO}

A palavra depressão é descrita no dicionário médico como o deslocamento para baixo ou para dentro, abaixamento ou redução da atividade funcional, tristeza mórbida. É sinônimo do ato de deprimir-se, debilitar-se, enfraquecer, causar angústia, abater-se, sofrer e angustiar-se. É comum que haja confusão entre depressão e tristeza ${ }^{1}$. A tristeza é considerada uma resposta afetiva normal às situações de perda, frustração, derrota ou outras adversidades; trata-se de um mecanismo de defesa adaptativo. Quando a tristeza permanece às diversas situações, perdendo seu caráter adaptativo e tornando-se uma constante, a depressão está estabelecida ${ }^{2}$. Seu quadro clínico é caracterizado basicamente por: humor depressivo e/ou falta de interesse e motivação, lentificação psicomotora (redução da energia mental e física) e redução ou ausência da capacidade hedônica (de sentir prazer, alegria, felicidade em situações cabíveis e proporcionais a elas) ${ }^{3}$.

Em relatório ${ }^{4}$, a Organização Mundial de Saúde (OMS) assinala que a depressão é grave e se situa em quarto lugar entre as principais causas de ônus entre todas as doenças e as perspectivas são ainda mais alarmantes quando apontam que, se persistir a incidência da depressão, até 2020 ela estará em segundo lugar. Em todo o mundo, somente a doença isquêmica cardíaca irá superá-la. Outros autores acrescentam ainda que os custos e as consequências da doença como perda de emprego, diminuição da produtividade no trabalho e mortes por suicídio são, de fato, preocupantes e incalculáveis ${ }^{5}$.

Apesar do avanço nas pesquisas e do reconhecimento da relevância clínica da depressão nas últimas décadas, sua etiologia ainda não está claramente compreendida. No entanto, há fortes razões para se acreditar que a depressão tem etiologia multifatorial, considera-se que a predisposição genética, eventos stressantes, conflitos intrapsíquicos, doença orgânica, ou a combinação entre eles, podem acarretar um estado depressivo ${ }^{6}$.

A pessoa com sintomas depressivos está presente, não apenas nos centros de atenção à saúde mental, mas também nos mais diversos lugares como escolas, comunidades, clínicas, hospitais e unidades de atenção básica ${ }^{7}$. Deste modo, é prerrogativa do enfermeiro o conhecimento adequado sobre enfermagem psiquiátrica, para que uma assistência qualificada seja prestada. Assim sendo, o enfermeiro deve possuir a capacidade e a responsabilidade de reconhecer os transtornos de humor e intervir sobre os mesmos de forma cabível.

Neste contexto, entretanto, Harada e Soares ${ }^{8}$ atentam sobre a afirmação da OMS de que os profissionais de enfermagem são despreparados no manejo das pessoas com transtorno de humor, bem como não observam os indicadores de sinais e sintomas nos pacientes atendidos e muitos não entendem que seja sua tarefa esta identificação.

Entende-se que os alunos de graduação de enfermagem precisam se perceber como pessoas importantes no processo educacional de formação pessoal e profissional e aproveitar as muitas possibilidades criadas durante o curso. É de fundamental importância aprender a mobilizar e integrar conhecimentos gerais de enfermagem em saúde mental e psiquiátrica para assistirem as pessoas com transtornos mentais. Estudos realizados por enfermeiras, tanto da área assistencial como do ensino de enfermagem psiquiátrica, nacionais e internacionais, apontam inúmeras dificuldades que alunos e têm para integrar conhecimentos que os habilitem a cuidar de pacientes com problemas emocionais e psiquiátricos e ingressarem nesta área ${ }^{9}$. Entretanto, ao se realizar uma busca nas bases de dados nacionais e internacionais, ainda nos deparamos com um pequeno número de artigos sobre a formação do enfermeiro em saúde mental, o que reforça a importância do presente estudo.

Em pesquisa ${ }^{10}$ sobre a motivação dos estudantes de enfermagem para ingressar na área da Saúde mental realizado no Reino Unido e Austrália, contatou-se que cerca de um terço dos entrevistados australianos indicaram que a saúde mental definitivamente não seria uma opção de carreira, enquanto que, no Reino Unido, apenas $8 \%$ não optariam pela área. Segundo o estudo, em ambos os grupos um maior nível 
de motivação para o trabalho em saúde mental emanava de alguma experiência pessoal e/ou experiência de trabalho/exposição aos cuidados de saúde mental, não estando ligada, portanto, ao ensino da psiquiatria na graduação. Sendo assim, inferiu-se que um maior enforque na exposição clínica psiquiátrica poderia melhorar a experiência profissional necessária para aumentar a motivação dos alunos para a enfermagem em saúde mental.

Um estudo ${ }^{11}$ buscou analisar o conhecimento de graduandos de enfermagem acerca da depressão e os principais resultados mostraram que quantitativamente, os alunos têm um bom conhecimento e opiniões pertinentes sobre o tema. Entretanto, nas respostas individuais, percebem-se lacunas no conhecimento que, provavelmente são relacionadas a falhas no ensino deste tema aos estudantes. Trata-se de um ponto que deve ser bastante discutido e explorado, pois é tarefa dos profissionais de enfermagem conhecer, acolher e prestar assistência de qualidade ao paciente psiquiátrico, identificando suas principais necessidades. Por isso é necessária uma formação profissional de qualidade, para que o enfermeiro possa reconhecer e atuar terapeuticamente junto à pessoa com transtorno depressivo.

Face às reflexões iniciais e com base no fato que o conhecimento norteia a conduta profissional, o presente estudo buscou investigar as concepções dos acadêmicos do Curso de Bacharelado em Enfermagem da Universidade Federal de Campina Grande, campus Cuité, acerca da depressão, bem como suas propostas para uma melhoria da qualidade do ensino, visto que a academia é um espaço dominante na divulgação deste conhecimento.

\section{MÉTODO}

Trata-se de um estudo exploratório com abordagem qualitativa. No estudo descritivo os fatos são observados, analisados, classificados e interpretados, sem que o pesquisador interfira neles, ou seja, os fenômenos são estudados, mas não manipulados pelo pesquisador. A pesquisa descritiva busca descobrir, com maior precisão possível, a frequência com que um fenômeno ocorre, sua relação e conexão com outros, sua natureza e suas características ${ }^{12}$.

A pesquisa foi realizada na Universidade Federal de Campina Grande (UFCG), no Centro de Educação e Saúde (CES), na cidade de Cuité, situado na localidade do Olho D'Água da Bica a $2 \mathrm{~km}$ do centro do município de Cuité, Paraíba.

Para selecionar a população do estudo, lançou-se mão do seguinte critério de inclusão: acadêmicos do Curso de Bacharelado em Enfermagem da UFCG campus Cuité - PB; a amostra foi selecionada baseada no seguinte critério de exclusão: acadêmicos que não estivessem cursando o último ano do curso.

A coleta foi realizada por meio de um questionário semiestruturado de abordagem direta aos acadêmicos concluintes de enfermagem em relação ao conhecimento sobre depressão.

Por se tratar de uma pesquisa envolvendo seres humanos, foram observados os princípios éticos, estabelecidos pela Resolução n 466/12 do Ministério da Saúde que preconiza no seu capítulo III que as pesquisas envolvendo seres humanos devem atender as exigências éticas e científicas fundamentais ${ }^{13}$.

Após a autorização do Comitê de Ética de Pesquisa (CEP), sob o CAAE 22123713.4.0000.5182 os dados foram coletados de forma conjunta entre os estudantes em sala de aula. Os dados referentes às questões subjetivas foram transcritos e categorizados de acordo com a Análise do Conteúdo ${ }^{14}$.

\section{RESULTADOS E DISCUSSÃO}

Para avaliar, de uma maneira objetiva, o conhecimento dos estudantes sobre a depressão, solicitou-se que os participantes respondessem à pergunta "Como você avalia seu conhecimento sobre o transtorno depressivo?", e apresentaram-se as opções em que os estudantes avaliaram seus conhecimentos como "ótimo, bom, regular ou péssimo". A análise revelou a existência de apenas duas categorias: 13 estudantes marcaram a alternativa "bom", totalizando 52\%, e 12 acadêmicos responderam "regular", totalizando $48 \%$. As demais opções não foram contempladas nas respostas. 
Comparando estes resultados com uma pesquisa $^{11}$ realizada com 26 estudantes do $4^{\circ}$ ano de Enfermagem, observa-se uma tênue divergência, tendo em vista que a maioria dos estudantes daquela pesquisa apresentou um alto conhecimento sobre a depressão, enquanto os deste estudo encontram-se distribuídos entre bom ou regular. Acredita-se que a disparidade da $^{11}$ cursaram recentemente as disciplinas de Saúde Mental e Psiquiatria, o que Ihes deu maiores condições de apresentar um conhecimento satisfatório sobre o tema. Enquanto os participantes deste estudo cursaram as disciplinas há mais de um ano e estão no último período da graduação, o que pode gerar certa insegurança quanto à sua futura atuação profissional.

Buscando-se uma abordagem mais completa e procurando interligar teoria e prática, o questionário prosseguiu com a seguinte questão: "Você acredita que os conhecimentos teóricos repassados na academia sobre a depressão são suficientes para a prática?". As categorias obtidas com a apreciação das respostas foram as seguintes:

SUFICIENTES: Nesta categoria foram inseridas as respostas em que os concluintes julgaram que o ensino da depressão foi repassado de maneira satisfatória, de modo a garantir um suporte adequado para a prática. Exemplo: "Sim. A parte teórica do assunto foi repassada de forma bastante clara e didática, facilitando bastante a prática." (A24).

Neste grupo de resposta encontraram-se duas subcategorias:

Lacunas práticas: Neste quesito, o aluno apresentou uma resposta adversativa, tendo em vista que julgava o conhecimento suficiente, embora reconhecesse a necessidade de um aperfeiçoamento na questão prática. Exemplo: "Um bom conhecimento foi adquirido, mas ainda existem algumas dúvidas em saber como Ihe dar de forma correta com o indivíduo com transtorno depressivo." (A2)

Sem justificativa: Nesta subcategoria, o acadêmico absteve-se de explicações mais aprofundadas. Exemplo: "Bom." (A17).

INSUFICIENTES: Nesta categoria incluíram-se as respostas onde os estudantes julgavam que o conhecimento transmitido sobre o transtorno depressivo não foi satisfatório para subsidiá-lo para o campo prático. Como a maioria dos entrevistados apresentou diferentes justificativas para tal opinião, foi necessária a criação de algumas subcategorias:

Necessidade de Aperfeiçoamento: Nesta subcategoria incluíram-se as respostas em que os estudantes julgaram que há necessidade de um maior aprofundamento acerca do tema para que o mesmo consiga atuar na prática de maneira eficaz e satisfatória. Exemplo: "Não. Acho que esse assunto deveria ser reforçado, pois não é raro nos deparar com pacientes que sofram com depressão. Tanto no ambiente hospitalar, quanto na atenção básica." (A16)

Conteúdo Superficial: Aqui se enquadraram as respostas dos acadêmicos que afirmaram que o conteúdo da depressão foi apresentado sem o devido aprofundamento. Exemplos: "Não, haja vista que o assunto foi visto em uma única aula, a qual a didática utilizada não foi adequada para nos preparar para a prática e sim favoreceu a um embasamento superficial e teórico." (A1).

Lacunas Práticas: Neste ensejo, incluíram-se as respostas em que os discentes acreditavam que houve um déficit na parte prática do assunto. Exemplo: "Não. Mesmo com a abordagem do tema em mais de uma disciplina, a teoria não é colocada em prática para firmar e desenvolver o que foi passado em sala de aula." (A5.)

Sem justificativa: Nesta subcategoria o aluno absteve-se de explicações mais aprofundadas. Exemplo: "Não." (A21).

Vivência extra-acadêmica: Neste quesito encaixa-se a resposta em que a aluna afirma que o conhecimento adquirido está associado somente ao senso comum, ou seja, decorrente da vivência fora do ambiente acadêmico. Exemplo: "Não. Grande parte do que eu sei sobre a doença está associado à vivência com minha avó que tinha Depressão." (A15).

A Tabela 1 apresenta as frequências e percentuais de respostas dadas a esta questão. 
Tabela 1. Frequências e percentuais das respostas dos acadêmicos da Universidade Federal de Campina Grande, campus Cuité, Paraíba, em relação à questão: "Você acredita que os conhecimentos teóricos repassados na academia sobre depressão são suficientes para a prática?" ( $N=25)$

\begin{tabular}{lcc}
\hline Categorias & Frequência & Percentual (\%) \\
\hline SUFICIENTES & 4 & 15,5 \\
- Lacunas práticas & 1 & 3,8 \\
- Sem Justificativa & 1 & 3,8 \\
INSUFICIENTES & & 30,8 \\
- Necessidade de aperfeiçoamento & 8 & 26,9 \\
- Lacunas práticas & 7 & 7,7 \\
- Conteúdo Superficial & 2 & 7,7 \\
- Sem justificativa & 2 & 3,8 \\
- Vivência extra-acadêmica & 1 & $\mathbf{1 0 0}$ \\
\hline Total & $\mathbf{2 6}$ & \\
\hline
\end{tabular}

Fonte: Dados da pesquisa, 2014.

Conforme apresentado na Tabela 1, pode-se verificar que a maior frequência de respostas encontra-se na subcategoria "Necessidade de Aperfeiçoamento" advinda da categoria "Insuficientes".

Observa-se que a maioria considerável dos alunos avalia seus conhecimentos insuficientes. No que tange à necessidade de aperfeiçoamento mencionada pelos estudantes, alguns autores ${ }^{15}$ defendem que o cuidar e o ensinar em enfermagem são indissociáveis. O cuidado envolve todo um aparato de informações que devem fundamentar o ensino e que precisam ser difundidos e articulados como um conhecimento que não termina em sala de aula, mas que possa ser considerado como o ponto de partida para uma reflexão que conduza à compreensão da prática, pois o conhecimento não é algo acabado, mas uma construção que se faz e refaz de forma dinâmica. A busca contínua de conhecimentos deve envolver leituras, questionamentos e os conhecimentos sobre essa realidade do processo cuidar e ensinar vivido pelo estudante.

Outra categoria que obteve relevante frequência foi aquela em que os estudantes consideram seus conhecimentos insuficientes por haver lacunas na prática. Este resultado aponta a necessidade cogente de um ensino mais aprofundado e, sobretudo, uma atuação mais efetiva e ampla no campo prático, pois se tratam de acadêmicos no último período da graduação que precisam estar devidamente preparados para reconhecer e lidar com o paciente depressivo. Tal fato é ressaltado por alguns autores ${ }^{7}$ que afirmam ser prerrogativa da enfermagem, em qualquer instituição de saúde, o reconhecimento dos sinais indicativos e intervenções adequadas em todas as pessoas que sofrem de transtorno depressivo.

A fim de propor uma reflexão acerca do tema, solicitou-se que os participantes da pesquisa respondessem à seguinte questão: "Você se sente capacitado para identificar os sinais e sintomas da depressão em um paciente não-diagnosticado?". A análise de conteúdo das respostas levou à criação das seguintes categorias:

NÃO: Aqui se incluíram as respostas em que os alunos afirmaram que não se sentem capacitados, pois se justificaram no fato de que julgam seu conhecimento insuficiente. Exemplo: "Não, pois tenho pouca leitura sobre o assunto e acho que os sintomas que eu poderia identificar não seriam suficientes para diagnosticar um paciente." (A1).

SIM: Nesta categoria, enquadraram-se as respostas em que os estudantes expuseram que se sentem capacitados, pois possuem conhecimento suficiente sobre o tema (5 respostas - 20\%). Exemplos: "Sim, pois estudamos todos os sinais e sintomas da depressão, e como o diagnóstico é essencialmente clínico, com base nesses sinais e sintomas é possível detectar o referido transtorno. Exemplos de sinais e sintomas: baixa autoestima; tristeza; desinteresse em realizar ati- 
vidades que antes realizava; isolamento; perda ou aumento do apetite; insônia; o indivíduo se sente incapaz de tudo, entre outros." (A7).

Determinadas respostas que também integraram esta categoria não apresentaram maiores justificativas, por exemplo: "Sim. A maioria deles." (A2).

TALVEZ: Já os concluintes que se encaixaram tas acreditando que, embora não possuam um

Fonte: Dados da Pesquisa, 2014. conhecimento tão abrangente acerca do tema, os sintomas da depressão são facilmente identificados. Exemplo: "Talvez. Existem sinais da depressão que são clássicos e facilmente identificados, mas que também podem ser confundidos com um quadro de tristeza." (A19). Nota-se que esta categoria foi a que apresentou uma maior frequência de respostas.

A Tabela 2 apresenta as frequências e percentuais de respostas dadas a esta questão.

Tabela 2. Frequências e percentuais das respostas dos acadêmicos da Universidade Federal de Campina Grande, campus Cuité, Paraíba, em relação à questão: "Você se sente capacitado para identificar os sinais e sintomas da depressão em um paciente não-diagnosticado?" ( $\mathrm{N}=25)$

\begin{tabular}{lcc}
\hline Categoria & Frequência & Percentual (\%) \\
\hline Não & 10 & 40 \\
Sim & 8 & 32 \\
Talvez & 7 & 28 \\
\hline TOTAL & $\mathbf{2 5}$ & $\mathbf{1 0 0}$ \\
\hline
\end{tabular}

Percebe-se que os participantes da pesquisa se consideram capazes de reconhecer uma pessoa com depressão e suas respostas denotam que possuem significativo conhecimento sobre os aspectos clínicos da depressão. Diante disto, constatou-se que os sinais e sintomas elencados pelos estudantes são semelhantes aos apresentados na literatura ${ }^{2,7,16-17}$. Os sintomas psíquicos, físicos e comportamentais da depressão, elencando os principais, respectivamente: humor depressivo, redução do prazer nas atividades antes consideradas como agradáveis, fadiga persistente; diminuição da capacidade de raciocinar, perda do apetite, alterações no sono; retraimento social, crises de choro, retardo e lentificação generalizada².

Analisando-se comparativamente o resultado desta questão a um dos quesitos de uma pesquisa $^{5}$ realizada com enfermeiros da rede básica de saúde, observa-se uma expressiva contradição tendo em vista que a maioria quase absoluta (90,4\%) dos entrevistados da referente pesquisa concorda que o enfermeiro tem plenas condições de detectar uma pessoa deprimida no seu dia a dia. Enquanto que neste estudo, os alunos distribuíram-se, majoritariamente, entre "não" e "talvez", julgando-se como incapazes ou parcialmente incapazes de detectar a depressão em um paciente não diagnosticado. Esta análise reforça claramente que a efetiva conduta profissional do enfermeiro deve se pautar não só nos conhecimentos teóricos, mas, sobretudo, na atuação prática.

Buscando analisar o conhecimento do acadêmico na perspectiva da assistência de enfermagem, solicitou-se que os mesmos respondessem à questão: "Na sua opinião, como a enfermagem deve atuar no tratamento e atenção ao paciente portador de transtorno depressivo?". A análise de conteúdo das respostas possibilitou a criação das seguintes categorias:

Suporte emocional: Aqui enquadraram-se as respostas que mencionaram que é papel fundamental da enfermagem todos os fatores que envolvem o apoio emocional, objetivando fortalecer o vínculo entre o profissional e o paciente. A atenção holística torna-se imprescindível, devendo ser realizada, sobretudo, com base no cuidado humanizado. Exemplo: "Através de escuta atenta, buscando investigar toda a história 
clínica deste paciente e tentando compreender seu problema. Um bom acolhimento e um cuidado humanizado também é fundamental." (A13)

Atenção Farmacológica: Esta categoria reuniu as respostas em que os estudantes mencionaram o tratamento farmacológico como ação da enfermagem. Exemplo: "Orientar e incentivar a importância do uso de medicamentos." (A10).

Atuação da equipe multiprofissional de saúde: Neste quesito, revelaram-se as respostas em que os alunos julgaram necessária uma ação de todos os profissionais de saúde para o sucesso do tratamento. Os estudantes acreditam que o encaminhamento a um profissional especializado também se torna imperativo. Exemplos: "Encaminhar a tratamento com profissional especializado (psicólogo)." (A2); "[...] O profissional deve ter, acima de tudo, postura e discrição e procurar apoio de um médico ou psicólogo" (A17).

Estratégias de Educação em Saúde: Nesta categoria estão elencadas as respostas que preconizam as orientações de enfermagem dadas tanto ao paciente quanto aos familiares, à continuidade do cuidado; bem como a realização de oficinas e palestras. Exemplo: "Oferecer estratégias que façam com ele ocupar o seu tempo (terapia ocupacional); acompanhar e orientar a família a respeito dos cuidados." (A10).

Ressocialização: Neste grupo estão as respostas que valorizaram o convívio social e a ressocialização do paciente como estratégia importante no tratamento. Exemplos: "Promovendo a ressocialização do paciente." (A9); "Incentivar o convívio social." (A10); "[...] possa reinserir o indivíduo na sociedade." (A12).

Não pertinente: Esta categoria contém a resposta que não se enquadra em nenhuma das demais categorias e que não atendeu ao que foi perguntado. Exemplo: "Primeiramente, o conhecimento sobre a temática deveria mais explorado para que o tratamento e a atenção fosse mais precisos." (A16).

A Tabela 3 apresenta as frequências e percentuais de respostas dadas a esta questão.

Tabela 3. Frequências e percentuais das respostas dos acadêmicos da Universidade Federal de Campina Grande, campus Cuité, Paraíba, em relação à questão: "Na sua opinião, como a enfermagem deve atuar no tratamento e atenção ao paciente portador de transtorno depressivo?". ( $N=25)$

\begin{tabular}{lcc}
\hline Categoria & Frequência & Percentual (\%) \\
\hline Suporte emocional & 22 & 42,3 \\
Atenção farmacológica & 10 & 19,2 \\
Atuação da equipe multiprofissional de saúde & 9 & 17,3 \\
Estratégias de educação em saúde & 7 & 13,5 \\
Ressocialização & 3 & 5,8 \\
Não Pertinente & 1 & 1,9 \\
\hline Total & $\mathbf{5 2}$ & $\mathbf{1 0 0}$ \\
\hline
\end{tabular}

Fonte: Dados da pesquisa, 2014.

De acordo com os dados expostos na Tabela 2 pôde-se contatar que a categoria "Suporte emocional" encontra-se em maioria considerável, seguida pela frequência de respostas dadas à categoria "Atenção farmacológica".

As respostas dos participantes que mencionaram o suporte emocional têm íntima relação com a assistência. As intervenções de enfermagem apresentadas por alguns autores ${ }^{18}$ estão expressivamente relacionadas ao apoio emocional, em suma, preconizam diálogo, apoio, aconselhamento, orientações e suporte familiar. Infere-se que os acadêmicos reconhecem que a depressão é um transtorno psíquico que acarreta consequências importantes, sobretudo no campo psicológico e comportamental e que é papel do enfermeiro atender a este paciente de maneira humanizada e holística. Este cuidado deve se pautar no estabelecimento de vínculos entre o profissional e o paciente. Diante disso, alguns autores ${ }^{15}$ alegam que o cuidar na enfermagem está embasado na criação de vínculos e 
confiança mútua, o que exige o estabelecimento de uma relação de empatia e receptividade com o cliente, que abrange a sensibilidade no tocar, no olhar no saber sentir e captar as emoções de quem estamos cuidando para poder cuidar.

A categoria "Atenção Farmacológica" criada a partir das respostas dos discentes é um resultado relevante, pois cerca de dois terços dos tratamento com antidepressivos ${ }^{19}$. O tratamento farmacológico da depressão visa proporcionar uma recuperação inicial do indivíduo, de forma a permitir que ele perceba a necessidade de permanecer em tratamento e para a manutenção do seu bem-estar e/ou para prevenir recaídas.

Estudos $^{7,11}$ constataram que alguns dos participantes das suas pesquisas - enfermeiros e estudantes de enfermagem, respectivamente também concordaram que é necessária a contribuição do enfermeiro para melhorar a adesão ao tratamento com antidepressivos. Esses estudos ${ }^{7,11}$ inferiram que isto se configura em uma postura de submissão ao médico, não valorizando as demais atividades do enfermeiro. Os resultados do presente estudo vão em desacordo com estas conclusões, tendo em vista que todos os estudantes que mencionaram a atenção farmacológica como atividade de enfermagem, complementaram suas respostas apresentando pelo menos duas das demais categorias aqui apresentadas, o que demonstra que os estudantes reconhecem que o papel da enfermagem na depressão vai além da atenção farmacológica.

A análise da categoria "Atuação da equipe multiprofissional" demonstra que os graduandos entendem a importância da atuação de toda a equipe multiprofissional na atenção a pessoa com depressão. Compreendem que o diagnóstico é realizado pelo profissional especializado, mas o enfermeiro pode e deve atuar reconhecendo os sintomas e tomando as devidas providências quanto ao encaminhamento e atuação terapêutica. Este resultado se coaduna aos de outra pesquisa ${ }^{20}$, em que os participantes mencionaram a ajuda médica e/ou psicológica. Segundo os autores ${ }^{20}$, isto se configura na responsabilidade profissional em saber até

onde permeia suas competências, valorizando o trabalho em equipe, o que possibilitará a integralidade do cuidado à pessoa deprimida.

Finalmente, entendemos que a educação em saúde, também citada pelos acadêmicos na assistência de enfermagem, é componente essencial da atenção de enfermagem a pessoa com transtorno depressivo, uma vez que é através deste método que o profissional pode garantir a continuidade do cuidado e a busca pelo bem-estar e qualidade de vida do cliente. O enfermeiro deve conceber uma visão do cuidado que valorize a subjetividade do indivíduo, ajudando-o a melhorar o conhecimento de si mesmo e de suas potencialidades, o que eleva sua autoestima, confiança, o que o incentivará a adotar atitudes positivas em relação a si próprio ${ }^{20}$.

Em relação às estratégias utilizadas na academia, perguntou-se aos entrevistados "De que maneira a depressão foi abordada nos componentes curriculares da sua graduação?", quando se realizou a análise de conteúdo das respostas, foi possível elaborar as seguintes categorias:

Método tradicional: Nesta categoria foram computadas as respostas em que os alunos afirmaram que o assunto foi transmitido através do método tradicional, com aulas expositivas e seminários. Exemplo: "Através de aulas teóricas e expositivas em data show, no decorrer da disciplina da Enfermagem em Psiquiatria e Saúde Mental. O tema também foi trabalhado em seminários." (A13).

De forma superficial: Esta categoria agrupou as respostas em que os participantes relataram que o estudo da depressão foi difundido de forma breve e superficial. Exemplo: "Brevemente em um dos conteúdos da disciplina de Psiquiatria e em alguns seminários em outras disciplinas." (A18).

Uso de dinâmicas: A resposta incluída nesta categoria foi aquela em que o estudante alegou que o conteúdo foi repassado através do uso de dinâmicas. Exemplo: "[...] fazia dinâmicas, interagindo bem com a turma, afim que os alunos fixem o conteúdo." (A7).

A Tabela 4 apresenta as frequências e percentuais de respostas dadas a esta questão. 
Tabela 4. Frequências e percentuais das respostas dos acadêmicos da Universidade Federal de Campina Grande, campus Cuité, Paraíba, em relação à questão: "De que maneira a depressão foi abordada nos componentes curriculares da sua graduação?". (N=25)

\begin{tabular}{lcc}
\hline Categoria & Frequência & Percentual (\%) \\
\hline Método Tradicional & 19 & 65,5 \\
Forma Superficial & 9 & 31 \\
Uso de dinâmicas & 1 & 3,5 \\
\hline TOTAL & $\mathbf{2 9}$ & $\mathbf{1 0 0}$ \\
\hline
\end{tabular}

Fonte: Dados da pesquisa, 2014.

De acordo com os dados apresentados na Tabela 4 é possível verificar que a maior parte das frequências se encontra na categoria "Método Tradicional". Este resultado apresentou-se de acordo com o esperado, uma vez que o método é a primeira escolha na maioria das instituições de ensino, tendo em vista a pluralidade de conteúdos que precisam ser ministrados em um curto período de tempo. Diante do exposto, uma das vantagens para a técnica da aula expositiva seria a economia de tempo para repasse do conteúdo. Também é citado pela autora que esta técnica supre a falta de bibliografia para o aluno e facilita sua compreensão sobre assuntos considerados complexos ${ }^{21}$.

Em contrapartida, a aula expositiva tem o objetivo de garantir apenas uma compreensão inicial do aluno, indispensável para a aprendizagem de um novo assunto ${ }^{16}$. Isso significa que uma aprendizagem total não pode ser alcançada, mas apenas um aprendizado inicial de informações básicas. Esta análise pode explicar o motivo dos participantes deste estudo relatarem sentir insegurança para lidar e reconhecer uma pessoa com depressão, mas, ao mesmo tempo, relatarem informações sobre os sinais e sintomas do distúrbio, demonstrando possuírem conhecimento teórico básico acerca do assunto.

Com a finalidade de conhecer as opiniões dos estudantes quanto às possíveis melhorias no ensino da depressão, perguntou-se: "Como você acredita que as disciplinas possam contemplar de uma maneira mais efetiva a temática da depressão?". A análise de conteúdo das respostas levou à seguinte categorização:

Articulação da teoria com a prática: Encontraram-se nesta categoria as respostas em que os estudantes acreditam ser necessária uma abordagem mais eficaz na prática. Exemplo: "[...] se o aluno tivesse a oportunidade de vivenciar a prática, assistindo holisticamente algum paciente com transtorno depressivo, seria bastante efetivo." (A11).

Estudos de Caso: Esta categoria reuniu as respostas em que os acadêmicos citaram a realização de estudos de caso, trabalhando-se o papel da enfermagem, como estratégia importante para o aprendizado. Exemplos: "Acredito que o estudo de casos seria interessante, pois assim teríamos exemplos para nós basear na prática." (A1).

Metodologias ativas: Foram incluídas nesta categoria as respostas em que os participantes mencionaram estratégias - sobretudo o uso de dinâmicas - onde o processo de ensino busca a participação ativa de todos os envolvidos, confrontando-se o modelo tradicional. Exemplos: "Na minha concepção, aulas dinâmicas com situações-problema poderiam contemplar de forma eficaz a temática em questão." (A8).

Reforço da teoria: Elencaram-se nesta categoria, as respostas em que os estudantes afiançam que o repasse teórico é importante, sendo necessário, portanto, uma abordagem mais aprofundada. Exemplo: "Além de abordar a temática da depressão e suas nuances, seus sinais, tratamento, deve ser mais efetivo e especifico no que tange a assistência da enfermagem ao paciente com este tipo de transtorno." (A19).

Não pertinente: A resposta do participante não se enquadra em nenhuma das demais categorias. Exemplo: "Sim." (A16)

A Tabela 5 apresenta as frequências e percentuais de respostas dadas a esta questão. 
Tabela 5. Frequências e percentuais das respostas dos acadêmicos da Universidade Federal de Campina Grande, campus Cuité, Paraíba, em relação à questão: "Como você acredita que as disciplinas possam contemplar de uma maneira mais efetiva a temática da depressão?". ( $N=25)$

\begin{tabular}{lcc}
\hline Categoria & Frequência & Percentual (\%) \\
\hline Articulação da teoria com a prática & 12 & 33,3 \\
Estudos de caso & 10 & 27,8 \\
Metodologias ativas & 9 & 25 \\
Reforço da teoria & 4 & 11,1 \\
Não pertinente & 1 & 2,8 \\
\hline TOTAL & $\mathbf{3 6}$ & $\mathbf{1 0 0}$ \\
\hline
\end{tabular}

Fonte: Dados da pesquisa, 2014.

A análise do percentual das respostas apresentadas da Tabela 5 revelou a predominância da categoria "Articulação da teoria com a prática". Este resultado se coaduna com as ideias de alguns autores ${ }^{22}$ que afirmam que o ensino, quando parte de situações reais ou se aproxima da realidade, estimula o estudo constante, a independência e responsabilidade. Nesse sentido, considera-se que a interdependência entre teoria e prática contribui para a construção de uma lógica de cuidado mais humanizado e integral, o que representa um avanço requerido na formação de profissionais de saúde.

Sendo assim, infere-se que o uso dos métodos para melhoria do ensino, propostos pelos discentes participantes da presente pesquisa, deve favorecer a participação do aluno como ser ativo do seu conhecimento, proporcionando-Ihe discernimento para lidar com as situações e desafios advindos da profissão. E, diante disso, o respeito à autonomia parece ser o melhor modo para a compreensão, por parte do binômio docente/discente, do processo de produção, expressão e apreensão do conhecimento, dentro de uma perspectiva de transformação da realidade, afinal, conhecer é transformar ${ }^{23}$.

\section{CONCLUSÃO}

A análise da percepção dos graduandos de enfermagem acerca do seu conhecimento sobre a depressão permitiu verificar que os mesmos percebem a abordagem do distúrbio como insuficiente para embasá-los para uma atuação profissional completa e eficaz. Os participantes afirmaram que há a necessidade de um maior aprofundamento e que uma abordagem eminentemente teórica não é suficiente. A realidade da carência de campo prático para o estágio das disciplinas Enfermagem na Saúde Mental e em Enfermagem Psiquiátrica é própria do Campus em questão, pois, por ser uma cidade de pequeno porte, há apenas um CAPS I para atender a demanda dos estágios de todos os cursos da cidade. Atrelado a isso, ainda há o problema da reduzida carga horária de estágios, o que representa um déficit na vivência prática aprofundada de todos os distúrbios estudados na disciplina de psiquiatria. Assim, consideramos que este quadro seja fator limitante na capacitação profissional quanto à área de saúde mental.

Foi satisfatório perceber que praticamente todos os concluintes descreveram uma assistência de enfermagem à depressão embasada no que é preconizado na literatura pertinente. Ou seja, mesmo julgando-se com um conhecimento de bom a regular e insuficiente para a atuação prática, os discentes demonstraram que saberão sim intervir adequadamente em um paciente com depressão e reconhecem que a enfermagem possui papel fundamental perante este público. O presente estudo procurou preencher lacunas de estudos anteriores sobre o tema, levando o foco para a análise da didática e do ensino. De uma forma geral, este objetivo foi alcançado. Concluímos que os graduandos reconhecem que o uso do método tradicional em sala de aula é necessário, mas que um meIhor e mais completo entendimento pode ser 
alcançado através do uso de metodologias ativas que façam o aluno um ser ativo do processo de aprendizado. O que nos remete que a prática da educação deve se dar de forma crítica e reflexiva capaz de promover conscientização e mudanças ${ }^{24}$. Adotar estratégias didáticas dessa natureza parece ser uma alternativa viável para a mudança da atual situação vivenciada pela comunidade acadêmica, haja vista que, a conscientização induz, necessariamente, à luta por melhores condições.
Destarte, acreditamos que os resultados aqui discutidos contribuem para uma reflexão acerca da importância do estudo do transtorno depressivo e de um ensino que capacite o estudante não só para atuar tecnicamente, mas para ser enfermeiro, com todas as prerrogativas que esta profissão carrega. Julga-se que futuras investigações possam contemplar a análise do Projeto Político do Curso de Bacharelado em Enfermagem para propor redefinições das ementas e a reorganização da oferta das disciplinas de acordo com os períodos letivos.

\section{REFERÊNCIAS}

1. Cândido MCFS, Furegato ARF. Atenção da enfermagem ao portador do transtorno depressivo: uma reflexão. Rev Eletr Saúde Mental Álcool e Drogas. [Internet]. 2005. [acesso em 2013 maio 14]. 1(2):1-13. Disponível em: <http://www.revistas. usp.br/smad/article/view/38627/41474>

2. Arantes DV. Depressão na Atenção Primária à Saúde. Rev Bras Méd Farm e Com, 2007, 2(8): 261-70.

3. Louzã Neto MRL, Elkis H. Psiquiatria Básica. 2a Edição. Porto Alegre: Artmed, 2007.

4. Organização Mundial de Saúde (OMS). Relatório Mundial da Saúde: Saúde Mental: Nova Concepção, Nova Esperança. 1 Ed. Lisboa, 2002.

5. Silva MCP, Stefanelli MC. Experiência de uma equipe de saúde mental comunitária na assistência de famílias convivendo com a depressão. Fam, Saúde e Desenv, 2002, 4(2): 89-97

6. Reis JSMS. Atividade Física: um complemento a considerar no tratamento da depressão. [Tese]. [Internet] Covilhã, Portugal: Universidade da Beira Interior; 2012. [Acesso em 2013 maio 14]. Disponível em: <http://www.fcsaude.ubi.pt/thesis/ upload../0/1150/tesefinaljoanasilvar.pdf>

7. Silva MCF, Furegato ARF, Costa Jr ML. Depressão: pontos de vista e conhecimento de enfermeiros da rede básica de saúde. Rev Latino-am Enferm, 2003, 11(1):7-13.

8. Harada OL, Soares MH. A percepção do agente comunitário de saúde para identificar a depressão. Rev Eletr Sáude Mental Álcool e Drogas. [Internet]. 2010. [acesso 2013 maio 14]. 6(2): 315-26. Disponível em: <http://pepsic.bvsalud. org/pdf/smad/v6n2/6.pdf>

9. Compoy MA, Merighi MAB, Stefanelli MC. O ensino de enfermagem em saúde mental e psiquiátrica: visão do professor e do aluno na perspectiva da fenomenologia social. Rev Latino-am Enfermagem. [Internet]. 2005; [acesso em 2015 agosto 01]. 13(2):165-72. Disponível em: <http://www.scielo.br/pdf/rlae/v13n2/v13n2a06.pdf>

10. Edward K, Warelow P, Hemingway S, Hercelinskyj G, Welch A, McAndrew S, Sterpheson J. Motivations of nursing students regarding their educational preparation for mental health nursing in Australia and the United Kingdom: a survey evaluation. BMC Nursing, 14 (29). ISSN 1472-6955.

11. Furegato AR, Nievas AFF, Silva ECS, Costa Jr. ML. Pontos de vista e conhecimentos dos sinais indicativos de depressão entre acadêmicos de enfermagem. Rev. Esc Enferm USP, 2004, 39(4): 401 - 08.

12. Andrade MM. Introdução à metodologia do trabalho científico. $6^{\mathrm{a}}$ Edição. São Paulo: Atlas, 2006.

13. Ministério da Saúde. Brasil. Conselho Nacional de Saúde. Diretrizes e normas regulamentada de pesquisa social. Comissão Nacional e Ética e Pesquisa CONEP Resolução 466/12 sobre a pesquisa envolvendo seres humanos. Brasília, 2012. 14. Bardin L. Análise de Conteúdo. Tradução Luís Atero Reto - Augusto Pinheiro. Lisboa: Persona. Edições 70, 2004.

15. Camacho ACLF, Santo FHE. Refletindo sobre o cuidar e o ensinar na enfermagem. Rev. Latino-am. Enferm, 2011, 9(1): 13-7.

16. Sadock BJ, Sadock VA. Compêndio de Psiquiatria: Ciências do comportamento e psiquiatria clínica. $9^{a}$ Ed. Porto Alegre: Artmed, 2007.

17. Louzã Neto MR, Elkis H. Psiquiatria Básica. $2^{\text {a }}$ Ed. Porto Alegre: Artmed, 2007.

18. Smeltzer SC, Bare BG, Hinkle JL, Cheever KH. Tratado de Enfermagem Médico-Cirúrgica. 12. Ed. Rio de Janeiro: Guanabara Koogan, 2013.

19. Máximo GC. Aspectos sociodemográficos da depressão e utilização de serviços de saúde no Brasil. 2010. [Tese]. [Internet]. Universidade Federal de Minas Gerais, Belo Horizonte, 2010 [acesso em 2013 maio 14]. Disponível em: <www. bibliotecadigital/ufmg.br/dspace/handle/1843/AMSA-8BCKKK>

20. Moreira GCD, Furegato ARF. Compreensão de alunos de enfermagem sobre a depressão e sobre o cuidado a pessoas deprimidas. Rev Tempus Actas Saúde Colet, 2010, 4(1): 211- 25. 
21. Lopes JP. Depressão: uma doença da contemporaneidade. Uma visão analítico-comportamental. 2005. [Trabalho de Conclusão de Curso]. [Internet]. Centro Universitário de Brasília, Brasília, 2005. [acesso em 2013 maio 14]. Disponível em: <http://repositorio.uniceub.br/bitstream/123456789/3069/2/20074556.pdf>

22. Marin MJS, Lima EFG, Paviotti AB, Matsuyama DT, Silva LKD, Gonzalez C et al. Aspectos das fortalezas e fragilidades no uso das Metodologias Ativas de Aprendizagem. Rev Bras Educ Méd, 2010, 1(34):13-20.

23. Miltre SM, Siqueira-Batista R, Girardi-de-Mendonça JM, Morais-Pinto NM, Meirelles CAB, Pinto-Porto C et al.Metodologias ativas de ensino-aprendizagem na formação profissional em saúde: debates atuais. Ciência \& Saúde coletiva, 2008, 13(2): 2133-44.

24. Freire P. Pedagogia do Oprimido. 15 Ed. Rio de Janeiro: Paz e Terra,1983. 